\title{
"Adentro y afuera: de lo femenino en el espacio", algunas reflexiones sobre la obra de María Isabel Naranjo Cano
}

\author{
Hilderman Cardona Rodas* \\ https://doi.org/10.22395/csye.v7n13a11
}

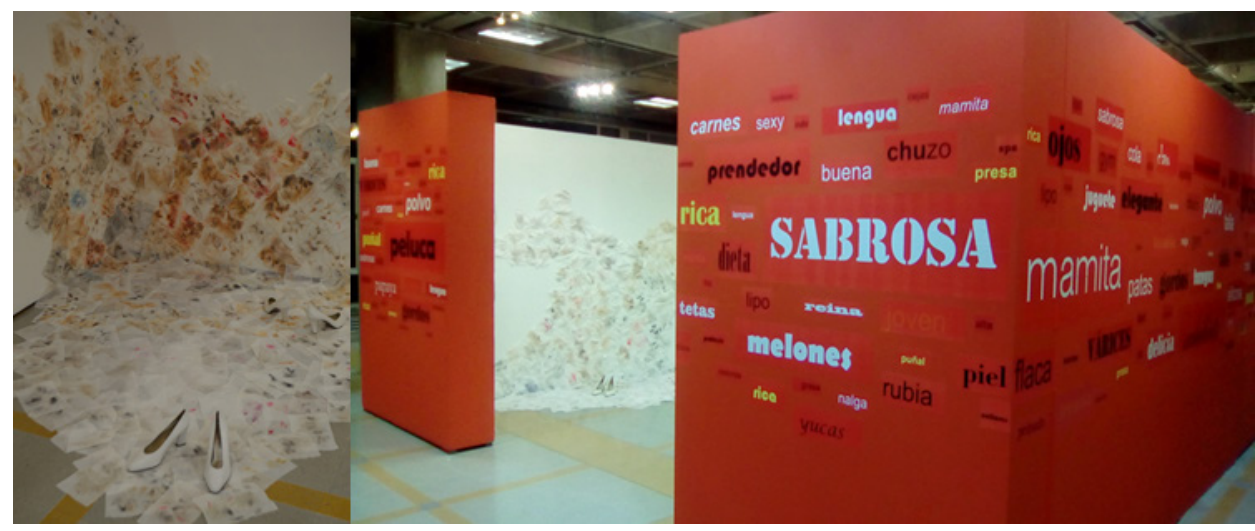

Detalles de la obra Adentro y afuera: de lo femenino en el espacio de María Isabel Naranjo Cano. Sala de Arte de la Biblioteca Central de la Universidad Pontificia Bolivariana (2016)

La artista plástica María Isabel Naranjo Cano, egresada de la Facultad de Artes de la Universidad Nacional de Colombia sede Medellín, con una maestría en Historia de la misma universidad, ha expuesto sus obras de forma individual y en colectivo en espacios nacionales e internacionales desde el 2000. Entre los espacios en los que ha exhibido de forma individual figuran:

- Maloca de la Universidad Nacional de Colombia, sede Medellín (2000)

- Sala U de la Facultad de Arquitectura de la Universidad Nacional de Colombia, sede Medellín (2010)

- Claustro San Ignacio de Medellín (2012)

- Biblioteca de la Universidad Pontificia Bolivariana, Medellín (2016).

Doctor en Antropología de la Universitat Rovira i Virgili de Tarragona (España). Magíster en Historia e historiador de la Universidad Nacional de Colombia, sede Medellín. Profesor de tiempo completo e investigador de la Facultad de Ciencias Sociales y Humanas de la Universidad de Medellín (Colombia) y coordinador del grupo de investigación Educación, Sociedad y Paz de la misma universidad. Correo electrónico: hcardona@udem.edu.co 
Las exposiciones en colectivo de las que ha hecho parte, cabe destacar:

- Imago Mundi, Mapa del Nuevo Arte, Venecia-Italia (2015)

- Premios Nacionales de Cultura en Colombia (de 2002 a 2007).

María Isabel Naranjo fue ganadora de la beca de creación artística Hangar. org, Barcelona en $2012^{* *}$. Ha sido curadora de exposiciones de arte en la Cámara de Comercio, Fundación Universitaria Bellas Artes, la Corporación Mujeres que Crean y la Casa Museo Pedro Nel Gómez, todas situadas en Medellín, Colombia. Asimismo, cursó y se certificó en Gestión de la Innovación en la Universidad de Pordue (Estados Unidos), Ruta N y Fundación Universitaria Bellas Artes (estas dos últimas de Medellín, Colombia).

En este número 13 de la revista Ciencias Sociales y Educación, la artista Naranjo participa con algunas fotos de su instalación "Adentro y afuera: de lo femenino en el espacio", la cual se llevó a cabo en la Sala de Arte de la Biblioteca Central de la Universidad Pontificia Bolivariana, Medellín en el 2016. En esta instalación ella despliega el vértigo de la experiencia estética en su encuentro con la memoria que se escenifica en los tejidos sensibles de lo que puede un cuerpo, en términos de Spinoza, en el despliegue del sentir, pensar, sufrir, hacer, saber o ser en la materialización de una obra. Lo femenino, inquietud dinámica en lo masculino, deja entrever el vínculo con el lenguaje que se hace carne y con el poder de la (des)figuración plástica. La relación que traza entre el adentro y el afuera para encontrarse con lo femenino navega en las ráfagas de piel que se exponen en los papeles teatralizados en la frontera de lo dicho, escuchado y palpado en los poros de una memoria viva y una escritura corporal de la experiencia.

La piel encarna y envuelve a la persona en el fuego intenso de las máscaras convertidas en palabras con sonoridades corpoimaginadas: carnes-lenguasabrosa-melones-rubia-nalga-tetas-peluca-polvo-mamita... ojos-flaca-deliciajuguete...; son las líneas expresivas de fuerza que le dan piel a la instalación, en un caparazón dispuesto a ser habitado por el espectador que fabula en la relación planteada por la artista. Allí, vemos cómo la virilidad del logos sentenció a lo femenino a la frágil textualidad del género, en el cual prevalecen los signos del poder y del monopolio que señalan y ensombrecen las formas, los fondos, las causas y los efectos que caracterizan a la mujer como el exponente accesorio de la sociedad; la mujer reducida a la domesticación de la intimidad, el recato, la moderación y el aplomo.

* Puede consultarse sobre estas becas de creación en https://hangar.org/es/news/petjades-en-vermell/ 
La selección de fotografías que integran la instalación de la artista Naranjo acompañan el ejercicio perceptivo de la mirada en el afuera de un acontecer que debe ser interpretado, es decir sentido y transformado en memoria de lo corpóreo de la diversidad de lo experimentado en la obra. Aquí lo que se ve, se toca y se pone enfrente palpita en la cinesis del lenguaje hiperestésico: una sensación de solidez en la autoconciencia de la mano que toca, analiza e informa en el estupor de lo más profundo de lo humano: la piel.

Agradecemos a la artista Naranjo haber compartido con los cuerpos sin órganos que se harán trueno en cada persona-máscara-epidermis que habite el número 13 de la revista Ciencias Sociales y Educación. 